\title{
Da extimidade da Psicanálise e seu lugar na polis
}

\section{On the extimity of psychoanalysis and its place at the polis}

\section{Sobre la extimidad del Psicoanálisis y su lugar en la polis}

\author{
Rita Manso* \\ Universidade do Estado do Rio de Janeiro, UERJ, Rio de Janeiro, Rio de Janeiro, \\ Brasil
}

\section{Marco Antonio Coutinho Jorge**}

Universidade do Estado do Rio de Janeiro, UERJ, Rio de Janeiro, Rio de Janeiro, Brasil

\section{Sonia Alberti $* * *$}

Universidade do Estado do Rio de Janeiro, UERJ, Rio de Janeiro, Rio de Janeiro, Brasil

\section{RESUMO}

Este artigo desenvolve considerações acerca do ensino e da pesquisa em Psicanálise na Universidade. A existência da Psicanálise de orientação lacaniana na América Latina tornou-se cada vez mais forte, seja por sua contínua atividade formadora nas escolas de Psicanálise, seja por sua intensa produção editorial e também pela sua numerosa presença na Universidade - como o lugar onde os diferentes saberes são confrontados. Considerando que toda pesquisa no campo da Psicanálise é clínica, e toda clínica em Psicanálise é do mal-estar, é essa a crucial noção para entender que há sempre um real em jogo, impossível de simbolizar, e isso é de estrutura. Tendo sido criada por um desejo de Freud de ajudar a diminuir a dor da alma, em sua proposta de troca do sofrimento neurótico pela infelicidade banal, o artigo pretende verificar o lugar da Psicanálise na Universidade a partir de seu trabalho sobre os restos deixados de lado pela ciência moderna que, ao mesmo tempo, cria a condição de possibilidade para sua existência. Considera-se a Psicanálise filha da ciência moderna, mas uma filha bastarda, ao mesmo tempo íntima e estranha, que lida com os dejetos dela, a ciência. Tendo a ciência excluído o sujeito de seu campo, é à Psicanálise quem cabe acolhê-lo em seu mal-estar.

Palavras-chave: Psicanálise, sujeito, mal-estar, Universidade.

\section{RESUMEN}

En este artículo se desarrolla consideraciones de la enseñanza y la investigación en psicoanálisis en la Universidad. La existencia del psicoanálisis lacaniana en América Latina se ha convertido cada vez más fuerte, ya sea en su actividad de formación continua en las escuelas de psicoanálisis, ya sea en su intensa producción editorial o por su numerosa presencia en la universidad como el lugar donde los diferentes saberes se 
enfrentan. Mientras que todas las investigaciones en el campo del psicoanálisis es clínico, se considera crucial entender que siempre hay un real, imposible de simbolizar, y eso es estructural. Después de haber sido creado por un deseo de Freud para ayudar a disminuir el dolor del alma en su propuesta de sustituir el sufrimiento neurótico por la infelicidad común, el documento tiene como objetivo verificar el lugar del psicoanálisis en la universidad, de su trabajo sobre los restos dejados de lado por la ciencia moderna que, al mismo tiempo, crea las condiciones de posibilidad de su existencia. Se considera el psicoanálisis hija de la ciencia moderna, pero una hija bastarda a la vez íntima y extraña, que trata de los residuos de la ciencia. El sujeto excluido de su campo es lo que el psicoanálisis deben recibe con su malestar.

Palabras-clave: Psicoanálisis, sujeto, malestar, Universidad.

\begin{abstract}
This article develops some considerations about teaching and researching in psychoanalysis at the University. The existence of Lacanian psychoanalysis in Latin America has become increasingly strong, either on its continuous training activity in the schools of psychoanalysis, either on its intense editorial production or their numerous presences at the university as the place where different knowledge are confronted. Whereas all research in the field of psychoanalysis is clinical, and every clinic in psychoanalysis is about discomfort, we consider this notion as crucial to understand that there is always a real in game, impossible to symbolize, and this is a fact of structure. Having been created by a desire of Freud to help decreasing the soul pain with his proposal to substitute the neurotic suffering by an ordinary unhappiness, this paper aims to verify the place of psychoanalysis at the university, from its work on the elements that are left aside by modern science which, at the same time, creates the condition of possibility for its existence. The psychoanalysis is considered the daughter of modern science, but a bastard daughter, at the same time intimate and strange, which turns out to deal with the waste of science. As science excluded the subject of its field, it is up to psychoanalysis to receive him in his discomfort.
\end{abstract}

Keywords: Psychoanalysis, subject, malaise, University.

\title{
Introdução
}

Os homens primeiramente sentem o necessário. Depois cuidam do útil. A seguir, do conveniente. Mais adiante, deleitam-se no prazer, dissolvendo-se no luxo. E, por fim, endoidecem ao dissiparem as coisas substanciais.

Giambattista Vico (1974)
Princípios de uma ciência nova, 1725

À guisa de introdução, este texto tem como fio condutor o lugar da Psicanálise no mundo de hoje e, em particular, seu lugar na ciência e na Universidade. Parte do desenvolvimento, com o pensamento freudiano, de que se a cultura é a possibilidade para o homem viver em sociedade, ela é, ao mesmo tempo, origem e fim de seu mal- 
estar - a Psicanálise o leva em conta desde sua criação e só há Psicanálise ali onde essa origem e fim são levados em conta. Em seguida, verifica as condições de possibilidade na história e na ciência, em relação à qual a Psicanálise é êxtima (íntima e ao mesmo tempo estranha, externa), para então retomar a Psicanálise em seu cerne, a clínica, e o modo como isso se coaduna, a partir de nossa experiência, com o ensino da Psicanálise na Universidade. Não é sem questões que esse texto termina.

Com a finalidade de desenvolver este artigo, e para que o leitor possa melhor nos acompanhar, enumeramos os itens que pretendemos aqui desenvolver:

\section{O nosso campo: o mal-estar}

\section{A Psicanálise e o discurso da ciência}

2.1 O advento do discurso da ciência abre a condição de possibilidade da criação da Psicanálise;

2.2 A Psicanálise decorre da ciência;

2.3 Exclusão do sujeito pela ciência moderna;

2.4 A Psicanálise é êxtima (íntima e estranha) ao discurso da ciência pois trata dos restos que aquela rejeita;

2.5 Inclusão do sujeito no próprio mal-estar que o causa;

2.6 A arte antecede a ciência e acolhe os restos desta;

2.7 A Psicanálise na Universidade: o mundo acadêmicocientífico.

\section{Considerações abertas}

\section{O nosso campo: o mal-estar}

Em 1980, Lacan embarcou em direção à Venezuela, atendendo o convite da psicanalista argentina Diana Rabinovich, para proferir um seminário que ficou conhecido como o seminário de Caracas. Em um escrito que divulgou antes de embarcar para a América Latina, Lacan afirmou que ali estava o futuro e que lhe interessava "ver o que se passa quando a minha pessoa não esmaga o que eu ensino" (Lacan, 1981, p. 14).

De lá para cá, a existência da Psicanálise de orientação lacaniana na América Latina tornou-se cada vez mais forte, seja por sua contínua atividade formadora nas escolas de Psicanálise, seja por sua intensa produção editorial, e também pela sua numerosa presença na Universidade, como o lugar onde os diferentes saberes são confrontados. No início deste século, Elisabeth Roudinesco observou que "os países latino-americanos (o Brasil e a Argentina, em especial) passaram à vanguarda do renascimento do freudismo, em virtude, em primeiro lugar, da força particular dos Departamentos de Psicologia instalados nas Universidades, lugares onde se privilegia 0 
ensino da Psicanálise em detrimento das outras disciplinas" (Roudinesco, 2000, p. 152).

Quanto a isso, lembramos que o crescimento da Psicanálise na Universidade - no Brasil e, em especial, no Rio de Janeiro, - foi catapultado com a inauguração do Programa de Teoria Psicanalítica da Universidade Federal do Rio de Janeiro (UFRJ), em 1988, visando a formação acadêmica nas áreas de ensino e pesquisa da Psicanálise. Seu primeiro coordenador foi o Prof. Luiz Alfredo Garcia-Roza. Dez anos depois, a Coordenação de Aperfeiçoamento de Pessoal de Nível Superior (CAPES) autorizou também a criação, na Universidade do Estado do Rio de Janeiro (UERJ), do Programa de Pesquisa e Clínica em Psicanálise, que teve como primeiro coordenador a Profa. Sonia Alberti. Em 2011, este Programa, com a parceria de diversos Programas de Pós-graduação que tinham como base teórica a Psicanálise, realizou o I Congresso Latino-americano de Psicanálise na Universidade, cujo tema foi "A clínica do mal-estar". O congresso contou com mais de mil participantes do Brasil e da América Latina e teve como Presidente de Honra a própria Professora da Universidade de Buenos Aires e psicanalista Diana Rabinovich, trinta e um anos depois de ter recebido Lacan em Caracas. O II Congresso Latino Latino-americano de Psicanálise na Universidade aconteceu em 2016, sob a organização da Universidade de São Paulo (USP) em parceria com a UERJ, caminhando-se para a criação da Associação Latinoamericana de Pesquisa em Psicanálise na Universidade.

A existência da clínica psicanalítica é hoje sustentada direta e indiretamente nas escolas de Psicanálise, nas Universidades, e na literatura específica, ao promoverem a transferência que a cultura porventura mantém com a Psicanálise. Pois concomitante à existência da transferência no sentido propriamente analítico, aquela com a qual cada analista tem que lidar em sua prática, há para os analistas igualmente a necessidade de sustentar no mundo a transferência com a própria Psicanálise. Antes de alguém se dirigir a um analista para nele localizar a sua suposição de saber que constituirá a mola da transferência e, portanto, do tratamento, é preciso que haja na cultura um genuíno espaço transferencial para a Psicanálise - e deste espaço quem cuida somos nós psicanalistas, com nossa palavra, oral ou escrita. Esta só é psicanalítica no momento em que se sustenta na própria Ética da Psicanálise, aquela definida por Lacan (1988) como a Ética do bem dizer. Daí o efeito de transmissão produzido pelo ensino de Lacan (iniciado entre nós já a partir de meados da década de 1970) revelar que, onde a Psicanálise preserva a sua ética ela se mantém viva. Sua vitalidade depende de os analistas, ancorados na Ética da Psicanálise, sustentarem sua particularidade discursiva, isto é, a singularidade do desejo do analista. Temas caríssimos à clínica psicanalítica e não dispensáveis no ambiente acadêmico, mas 
justamente por isso, necessários de serem aprofundados em outra ocasião.

Propomos que a "longa desenvoltura mantida em relação ao saber" (Lacan, 2003b, p. 220), com a qual Lacan qualifica a genialidade de Freud, não é de modo algum incompatível com a Universidade. Ao contrário, a universidade parece manter uma relação com a formação do psicanalista, quando Freud a nomeou em associação com uma verdadeira universitas literarum, que incluiria o ensino de arte, literatura, filosofia, religião, ciência... Segundo ele, as criações humanas deveriam ser íntimas daquele que exerce a Psicanálise, mesmo se ele próprio já observava que, quanto à formação dos analistas propriamente dita, seu lugar seria êxtimo a ela, o que atualmente ocorre nas sociedades e escolas com esse fim, apoiadas no tripé: ensino, supervisão e análise pessoal. Sabemos que na "Universidade o tout savoir está presente, é inevitável. Mas, como barreira a esse tudo saber, temos a produção de cada um que, além de contar como unidade de valor, retorna para o sujeito trazendo algo de sua verdade que se articula com um saber" (Figueiredo, 2011, p. 192).

$\mathrm{Na}$ universidade se dá o confronto do saber que agencia o outro como objeto para fazer dele um sujeito bem pensante com o saber de si, essencial para o reconhecimento da singularidade do sujeito. Assim, a pesquisa do caso a caso que especifica o tratamento analítico pode ser confrontada com o universal da construção teórica. Freud já afirmara certa vez que se preocupava com o fato isolado e esperava que dele jorrasse o universal (cf. Jorge \& Ferreira, 2005, p.10-24 e Freud, 1975d, p. 44). E não será na Universidade que adquire mais sentido a poética formulação de Lacan segundo a qual "um sorriso se multiplica quando é o de uma pessoa jovem"? (Lacan, 1970/2003d, p. 389). De todo modo, "nada garante que do ensino resulte um saber" (Figueiredo, 2011, p. 193).

O evento sobre $A$ clínica do mal-estar - introduziu um sintagma que fez parelha com aquele famoso sintagma cunhado por Freud em seu ensaio sobre $O$ mal-estar na civilização (1974), escrito no novo sopro de reflexão trazido pela virada apresentada em 1920 no ensaio Maisalém do princípio de prazer. De fato, Freud passa a tematizar quase exclusivamente a cultura a partir do momento em que propõe esse novo instrumento teórico, a pulsão de morte - nomeada por ele de diferentes maneiras: pulsão de destruição, pulsão agressiva, pulsão de apoderamento, pulsão de crueldade ou simplesmente destrutividade -, todas elas designando a característica mais basal inerente às pulsões: seu caráter arrebatador sua busca imperiosa e indomável de satisfação que a torna apta a aderir a qualquer objeto, inclusive - e sobretudo - o mortífero. Lacan chamará de gozo a exigência da pulsão, ela busca a descarga, e nesse ato, goza. Assim, a pulsão busca sua própria extinção, sua morte. Em contraposição à 
pulsão de morte, Freud mantém a pulsão sexual, que ele chamará agora pulsão de vida ou Eros: essa sim é conservadora, interessada em formar unidades cada vez maiores, e que Lacan vincula à dimensão da linguagem, da cultura, do laço social, pois o "Eros unificador pode eliminar toda e qualquer diferença, sendo necessária a pulsão de morte para separar, produzir disjunções e rupturas" (Alberti et alli, 2014, p. 100). Em consequência de Eros, o sujeito se insere numa cultura, na busca de alguma garantia para a sobrevivência. A cultura, enquanto formação humana "tem, por essência, e não por acaso, de refrear o gozo" (Lacan, 2003c, p. 362). Mas a cultura, como dizia Freud, é fonte de insatisfação constante, 0 que não impede que ela própria ofereça seus sucedâneos como uma forma de compensação ao preço que é exigido dos sujeitos que a compõem.

A clínica do mal-estar é, propriamente falando, a clínica da Psicanálise, uma vez que o mal-estar é inarredável e assume diferentes formas em cada cultura e em cada época. Assim, quando Freud fala de mal-estar na cultura, ele não se refere a nenhum malestar em particular, nem a nenhuma cultura específica: o mal-estar é inerente à cultura enquanto tal e onde a houver ele estará presente. Pois, segundo Freud, a cultura é edificada sobre a renúncia pulsional, e ela pressupõe precisamente a não-satisfação (repressão, recalque e outros mecanismos mais) de poderosas pulsões.

Quanto à renúncia pulsional - sobre a qual, aliás, Freud chega a afirmar que ela é impossível, uma vez que não renunciamos a nada, apenas substituímos um objeto por outro - podemos segmentar a reflexão freudiana em dois grandes momentos: o primeiro, francamente exposto em 1908 no luminoso e breve ensaio sobre a Moral sexual 'civilizada' e doença nervosa moderna (1976a), o segundo, no Mal-estar na civilização, livro que recebeu incialmente o nome de $A$ infelicidade na cultura, depois $A$ felicidade na cultura, até chegar ao mal-estar na cultura! É preciso dizer que, contrariamente ao que se vê ser afirmado precipitadamente, não há pessimismo em Freud nem em Lacan. Como ponderou Jackie Pigeaud, o livro Malestar na civilização é uma obra fraternal, que ele compara ao $D a$ tranquilidade da alma, do filósofo latino Sêneca, obra sobre a relação entre a moderação e a felicidade (Pigeaud, 2008, p. 82). Se Sêneca afirma ali que "sempre é vicioso o que está em excesso" (2010, p. 64), Freud repetirá, por sua vez, que o excesso traz em si o germe de sua própria destruição, pois "qualquer escolha levada a um extremo condena o indivíduo a ser exposto a perigos, que surgem caso uma técnica de viver, escolhida como exclusiva, mostre-se inadequada. Assim como o negociante cauteloso evita empregar todo seu capital num só negócio, assim também, talvez, a sabedoria popular nos aconselhe a não buscar a totalidade de nossa satisfação numa só aspiração" (Freud, 1974, p.103). 
No primeiro texto ao qual nos referimos, Freud defende uma liberdade sexual sem a qual a cultura adoece os sujeitos e ironiza mordazmente a moral da cultura ao grafar insistentemente com aspas o termo "cultural" quando ele ocorre no sintagma "moral 'cultural'" (Freud, 1976a), Freud conjectura a existência de três fases sucessivas no tocante à evolução da humanidade no que diz respeito à aquiescência da satisfação sexual: a primeira, na qual a pulsão se exercia livremente em qualquer forma de manifestação sexual; a segunda na qual a sexualidade ficou restrita à atividade da reprodução e perdeu sua característica primordial: a de busca de satisfação e prazer desconectada dos ciclos reprodutivos encontrados na atividade sexual animal; a terceira, na qual a própria reprodução ficou restrita à legitimação através do casamento. O afunilamento da liberdade sexual presente nesses três estágios de evolução implicam, é claro, o recalque e a neurose.

Mas a sexualidade hoje parece ter reconquistado o território perdido ao longo da evolução retraçada por Freud. Hoje - desde o advento da pílula anticoncepcional nos anos 1960 e outras formas seguras de contracepção; o retorno da aceitação pela cultura da homossexualidade como uma manifestação sexual legítima; e as novas tecnologias de reprodução - o sujeito conquistou a possibilidade de encontrar satisfação de forma inteiramente independente da finalidade da reprodução. Assim como a própria reprodução, por sua vez, encontrou formas de se desvencilhar da atividade sexual (fecundação in vitro). Se os avanços da pesquisa científica foram decisivos para o advento de diferentes formas de liberação sexual, a própria Psicanálise incidiu na cultura com um acentuado poder transformador, através de sua teoria e de sua clínica (Braunstein, 2011, p. 48). E ela também nos oferece lentes para entender os efeitos causados por essas transformações no âmbito da cultura no século XXI.

A partir de 1920, uma sequência de textos de Freud trará em seu bojo a dimensão da destruição inerente ao pulsional: o vetor masoquista e o vetor sádico explicitam as duas direções que a pulsão de morte pode assumir em relação ao objeto: em direção ao próprio eu ou em direção ao objeto sexual. No Século $X X$, como ironizou Eugénie Lemoine-Luccioni, se o homem apaixonado e desiludido costuma dizer para a mulher "se você me abandonar, eu te mato", a mulher que sofre da mesma dor dirá "se você me abandonar, eu me mato" (Lemoine-Luccioni, 1979, p.73).Se a sexualidade está ligada a Eros, a destruição está ligada a Tânatos e eles andam sempre um ao lado do outro. A pulsão de morte está assim associada (fusionada, diz Freud) à pulsão sexual e, como por detrás do objeto amoroso se esconde sempre a Coisa devastadora que ameaça, a perda do objeto implica o confronto com um gozo mortífero. 
O medo, que se revela na teorização atual de alguns analistas, de que a sociedade teria se tornado perversa, com uma ideologia de que "qualquer desejo deve ser satisfeito", manifesta a incompreensão da estrutura tal como Freud a revelou ao introduzir a dimensão do recalque originário em 1915. Primeiro, porque promover 0 desrecalcamento não implica, necessariamente, a busca de satisfação direta da pulsão (embora esse campo seja aberto com ele), mas há ainda a sublimação e o esquecido juízo de condenação conjecturado por Freud. Além disso, o desrecalcamento tem limite, pois o que não se pode esquecer é que, mais além do proibido, há o impossível.

O impossível não é o proibido: a categoria de real, introduzida por Lacan para retificar as elaborações freudianas em torno da noção de realidade, traz em seu bojo o impossível enquanto inerente à satisfação pulsional. Ao introduzir a categoria de real na Psicanálise, Lacan dotou-a de condições para repensar a clínica e a cultura. O impossível não é o proibido, e se o não da interdição opera o recalque secundário (produzido pela parte inconsciente do eu), quanto ao recalque originário, este é veiculado apenas pelo contra-investimento constituído pelo furo da falta de objeto. Se o verdadeiro traumatisme é o trou matisme, como postula Lacan, jogando com o equívoco em francês entre traumatismo e trou (buraco), cabe indagar: qual a diferença do estatuto do "não" no campo do proibido e no campo do impossível?

Observamos que as teorias que afirmam que o sujeito de hoje não é mais o de Freud e Lacan parecem não compreender, que não se passa da neurose para a perversão nem mesmo pelo desrecalcamento; ao contrário, Lacan se empenhou em demonstrar que a perversão se distingue da neurose por consistir numa determinada posição subjetiva particular e não apenas na presença positivada de pulsões que estão recalcadas na neurose.

\section{A Psicanálise e o discurso da ciência}

Toda pesquisa no campo da Psicanálise é clínica, e toda clínica em Psicanálise é do mal-estar. Qual mal-estar? O de que há sempre um real em jogo, impossível de simbolizar, e isso é de estrutura. A Psicanálise foi criada por um desejo de Freud, digamos, a princípio, de ajudar a diminuir a dor da alma: a troca do sofrimento neurótico pela infelicidade banal. Assim, com esta questão em nosso horizonte, continuamos com o intuito de verificar o lugar da Psicanálise na Universidade, para o que é preciso retomar algumas orientações de saída. Seguimos agora os itens apontados no início. 


\subsection{O advento do discurso da ciência abre a condição de possibilidade da criação da Psicanálise}

Situar a Psicanálise na universidade, a partir das diretrizes dadas por Freud, tanto em 1919, quanto em 1926, ou seja, tanto em sua carta aos estudantes de medicina de Budapest, "A Psicanálise deve ser ensinada nas Universidades?", quanto em "A Psicanálise leiga", e de Lacan, em 1958, seu primeiro discurso em Roma, é situá-la na articulação com os outros saberes cujos desenvolvimentos puderam decorrer do fato de que instituiu-se um novo discurso, no século XVII, o discurso da ciência (sobre isso, consultar, por exemplo, Barros, 2012; Alberti \& Elia, 2008 e Fink, 1998). Esse novo discurso construiu uma nova realidade, ou melhor, algumas novas realidades, tantas quantas há ciências, e agrupadas em dois grandes conjuntos Naturwissenschaft e Geisteswissenschaft, ciências da natureza e ciências do espírito (ou da cultura ou humanas). O que se observa é que, para cada ciência, há uma forma particular de nomeação das coisas, de conceituação do que se especifica como seu objeto de estudo em sua leitura do real. O advento do discurso da ciência abre a condição de possibilidade de criação da Psicanálise, como de todas as ciências chamadas humanas.

Essa busca por uma forma de recobrir o real encontra-se na obra freudiana através de sua forte aposta no projeto da modernidade - é possível ler nas entrelinhas seu desapontamento com a ciência moderna a partir, justamente, do texto $O$ mal-estar na civilização, escrito em 1929 - cujo ápice seria a vitória da razão (logos) sobre a necessidade (ananké), que aliás era o slogan do Iluminismo. Entende-se então porque Freud, durante muito tempo, acreditou em um ideal da ciência (Barros, 2012).

Milner (1996) assinala com muita propriedade essa questão ao constatar que é verdade que o homem "sempre precisa de representações; em particular, é difícil evitar, quando recorremos ao ideal da ciência, como o fazia Freud, que tenhamos uma representação do que deve ser a ciência, e é isso uma ciência ideal" (Milner, 1996, p.30). Mas continua dizendo que, ao contrário, Lacan não acredita nisso, em uma ciência ideal, pois

já que não há ideal da ciência em relação à Psicanálise, tampouco há para ela ciência ideal. A Psicanálise encontrará em si mesma os fundamentos de seus princípios e métodos. [...] Melhor, ela se verá suficientemente segura para poder questionar a ciência. 'O que é uma ciência que inclui a Psicanálise?' (Milner, 1996, p. 31). 


\subsection{A Psicanálise decorre da ciência}

Não tivesse havido a instituição do discurso da ciência, a Psicanálise não teria sido possível, ela é filha dele e herdeira de seus avatares que, ainda hoje, mais de três séculos depois, insistem em instituir-se, o que não é fácil porque o ser falante - nós, a humanidade - viveu muito mais tempo sem ele do que com ele, de modo que as racionalidades, ainda hoje, na maioria das vezes continuam trilhando vias que the são anteriores. Senão vejamos: mesmo depois de a astronomia ter rompido com a astrologia, para quantos esta não se confunde ainda com aquela... Até mesmo Auguste Comte, apesar de seu positivismo, vaticinara que jamais se poderia distinguir a composição química dos astros, na mesma época em que a física começava a estudar o espectro a partir da luz proveniente dos astros, espectro que permitiu, justamente, identificar sua composição química!

Em De um discurso que não fosse semblante (Lacan, 2009), seminário 18, Lacan demonstra como todo discurso é artifício significante, indo ao gozo como o que aponta para o real da pulsão que anima em letra todo sujeito. Mas a Psicanálise, como dissemos, é filha do discurso da ciência, e não teria surgido se do Outro não brotasse a necessidade de sua existência.

\subsection{Exclusão do sujeito pela ciência moderna}

A história do pensamento é longa! Mas alguma coisa dele está lá desde sempre! Inicialmente, o que os estruturalistas puderam estabelecer no século XX: a importância, no que tange ao mundo do ser falante, de ele ter sido identificado pela linguagem, com a qual 0 nomeamos e cujos significantes utilizamos para nos identificar. A partir disso estabeleceu-se um jogo de combinatórias, de alternâncias, e é esse jogo de combinatórias "que hoje dá seu estatuto ao inconsciente" (Lacan, 1985a, p. 25). Em seguida, para além do fato de este mundo ser nomeado, desde o início da história de uma ciência que ainda não era a moderna, tais combinatórias necessariamente, desde sempre, deixaram um enigma. Retomando a história da ciência chinesa, forte no estudo dos céus numa época muito precoce, baseada nos princípios Yin e Yang, Lacan identifica nas alternâncias entre esses termos, nessas combinatórias, o que chama - de forma que ele próprio qualifica um pouco extremada -, de uma ciência primitiva ou técnica sexual, a testemunhar o fato de que o pensamento é, de saída, marcado pelo impossível do sexual.

Ciência enriquecida de observações perfeitamente válidas (Lacan, 1985a), em que tudo era referido à combinatória de Yin e Yang, o frio e o quente, a terra e a água, a reproduzirem os enigmas da sexualidade. Então, a ciência trazia consigo o sexual. Freud também 
já o identificara, quando observava a correlação entre o desejo de saber - como se traduziu sua Wissbegierde - e a curiosidade sexual. Então, a ruptura introduzida pela ciência moderna se dá no momento em que um sujeito emerge disso, é o sujeito da ciência que ela mesma foraclui, sujeito inconsciente como remanescente da junção arcaica do pensamento com a realidade sexual (Lacan, 1985a).

A proximidade da Psicanálise com o trabalho de pesquisa científica que se quer neutro acaba quando Freud chama a atenção para o fato, recalcado pela ciência, de que em qualquer observação entra em cena o aparelho psíquico do observador, coisa que a ciência insistia, como denuncia Lacan, em foracluir. É assim que Freud afirma que "toda ciência se baseia em observações e experiências a que se chegou através do veículo do nosso aparelho psíquico. Mas visto que a nossa ciência tem por assunto esse próprio aparelho, a analogia acaba aqui" (negrito nosso, Freud, 1975c, p. 184). E é justamente por isso que há um campo autointitulado científico que a coloca de lado.

\subsection{A Psicanálise é êxtima (íntima e estranha) ao discurso da ciência pois trata dos restos que aquela rejeita}

Não só por isso, no entanto. Na realidade, a Psicanálise-filha-dodiscurso-da-ciência é também exterior à ciência, o que não é exatamente um paradoxo, porque como filha daquele não precisaria ser ciência. É que a Psicanálise, justamente por ser filha do discurso da ciência, mas bastarda, se ocupa do sujeito que é excluído da ciência, e este, o sujeito, por não ter lugar na ciência, presentifica o mal-estar que ela produz. É resto dela, dejeto, real, impossível de ser controlado pela ciência, ele é cuspido. E a Psicanálise o acolhe.

\subsection{Inclusão do sujeito no próprio mal-estar que o causa}

A ciência como tal inscreve significantes - sob a forma de conceitos no real e, em função disso, é saber. Se tomamos emprestado de Lacan, em seu Seminário De um Outro ao outro, a articulação que desenvolve entre S1 e S2 quanto à ciência, poderíamos equivaler: na relação com o Um, no seminário 19, "... Ou pior", o saber se tece (Lacan, 2012). Se há o Um do início da existência da filosofia, que constituiu um mundo do saber a partir da ideia de que há um Um Deus, universal, mundo das ideias (Platão), Ser (Aristóteles) - é na relação com um pensamento que ele se constituiu.

Garantia do sujeito que o pensa, o Um do início é o Outro (A) do sujeito. Diferentemente da filosofia, no entanto, como saber, a ciência se sabe produto de um sujeito pensante, mas no momento mesmo em que se formula como conhecimento, já exclui aquele, o sujeito. E então novamente se busca avançar com mais um saber que 
inclui o sujeito porque é ele o sujeito pensante, mas de novo, no momento em que se formula como saber, já exclui o sujeito. Se em 1901 Russel pode fazer disso um paradoxo, Freud recebia Dora, Berta von Pappenheim, em seu consultório! E lhe perguntava: qual é a sua responsabilidade no mal-estar de que se queixa?

\subsection{A arte antecede a ciência e acolhe os restos desta}

Freud conjecturou sobre a arte enquanto possuindo um valor cultural que permite entender psicanaliticamente a recusa da guerra pelos pacifistas (Rey-Flaud, 2002, p.67). É certo que se Psicanálise e arte mantêm uma relação de enriquecimento mútuo isso se deve ao fato de que ambas lidam com a falta inerente ao desejo e, portanto, entronizam em suas operações simbólicas e imaginárias o real da estrutura.

Se sempre foi no campo das artes que melhor se falou do sujeito, o que levou tanto Freud quanto Lacan a postularem que os artistas precedem os psicanalistas, na mancha do quadro - de Os embaixadores (Holbein, 1553), de As meninas (Velasquez, 1656) -, na narrativa disruptiva de um texto literário - Joyce, 1939, Lispector, 1973 -, na deformidade de uma escultura - Balzac de Rodin, 1898, Marsyas de Kapoor, 2002 -, nas artes como campo em que se imaginariza o simbólico e seu furo, o real, é da clínica que isso retorna para o psicanalista.

Se a arte está a serviço do que não se encaixa, do quê para nada serve, dos restos despejados pela ciência, a Psicanálise é dela solidária. A arte e a Psicanálise recolhem esses restos e se colocam a serviço da manutenção e preservação da capacidade de desejar dos sujeitos. A Psicanálise é uma espécie de guardiã da falta, do nada que nela habita. O nada é aqui o pequeno vazio, ou o objeto $a$, ou talvez um quarto nó que sustenta, amarra e faz girar a experiência humana entre os registros imaginário, simbólico e real. Não se pode afirmar que a arte não serve para nada. Ela serve para que possamos, no fugaz momento da contemplação, repousar as armas das defesas (Lacan, 1985a) impostas pelo mal-estar engendrado pelo processo civilizatório, pela entrada na linguagem. Contudo, a arte também escancara o horror, jogando, olhos adentro, a miséria humana. Basta ver Guernica (1937), de Picasso ou o quadro de Goya, Saturno devorando seus filhos (1819-1823). Ontem e hoje. Tanto podemos passear sobre uma cena campestre, como num quadro de cores suaves de Renoir (1841-1919), nos maravilharmos ou horrorizarmos com a exposição da genitália feminina em $A$ origem do mundo (1866), de Gustave Courbet, ou com a Medusa (1597), de Caravaggio, terrificada diante do reflexo de sua própria morte no escudo de Jasão, ou com os quadros realistas e hipnotizantes de 
Lucien Freud (1922-2011) expondo na tela a angústia da finitude (Barros, 2016).

Será a Psicanálise, perguntamos, a música que na nossa cultura consegue, como a lira de Orfeu, dobrar o monstro que há em cada sujeito pedindo sua vida no gozo absoluto?

\subsection{A Psicanálise na Universidade: o mundo acadêmico- científico}

O sujeito excetuado que a clínica psicanalítica presentifica especifica seu campo, inclusive na Universidade, mesmo se nela só se trabalha com os efeitos experimentados na Psicanálise pura que tem lugar em um contexto bem longe da Universidade. Como afirmamos no início desse artigo, toda pesquisa no campo da Psicanálise é clínica, e toda clínica em Psicanálise é do mal-estar. Mal-estar que indica que, na estrutura, há sempre um real em jogo, impossível de simbolizar.

Em 29 de abril de 1964, Lacan desenvolve isso da seguinte maneira: "a transferência é a colocação em ato da realidade do inconsciente" (1985a, p. 139). Em 1967, estabelece duas formas de incidência da transferência: o trabalho em transferência e a transferência de trabalho (2003c). A primeira é a que se dá na Psicanálise pura, o trabalho - "Recordar, repetir, elaborar" (Freud, 1976b) - do analisante; a segunda é a que se dá na articulação com os textos, entre pares, visando o que cada sujeito elabora de sua relação com a causa freudiana com os outros. Se a transferência é a base da clínica em Psicanálise, então a clínica está em ambas essas formas, e com ela o mal-estar causado pelo fato de que há o impossível. A Psicanálise na Universidade imprescinde disso! Se somos psicanalistas e professores ou pesquisadores que trabalham na Universidade, imprescindimos disso! Senão não seremos psicanalistas e professores ou pesquisadores na Universidade, não transmitiremos o que pode a Psicanálise no contexto da universidade, nem tampouco saberemos aproveitar o que a universidade pode contribuir para situar em que o sujeito do discurso da ciência - e dela excluído pode avançar para persistir.

Lacan (1975) propõe que ele seja sintoma do que não vai bem no discurso vigente. Pedra no meio do caminho, conforme Drummond. Se não houver mais mal-estar, já não será sujeito ou sintoma, mas no caso de se curar do mal-estar, será sinal de que a Psicanálise morreu. Que persista, então, o próprio mal-estar! Como persiste no cientista que se angustia com a própria ciência que produz, conforme as muitas versões disso nas ficções científicas.

Como, por exemplo, o tema referido por Lacan em 1974 (1975), na conferência intitulada $A$ terceira, em Roma, dos efeitos de trabalhos em laboratórios que podem fazer surgir, na imaginação dos cientistas, as lúnulas de vida própria a escorregarem por debaixo das 
portas, invadindo o mundo dos seres falantes, acabando com eles. Lembremo-nos da Coisa do filme $A$ Bolha, de Irving $\mathrm{H}$. Millgateis, em 1958, com Steve McQueen, ou de Alien: O Oitavo Passageiro, de Ridley Scott, de 1979:

[...] E quando os biólogos [...] se impõem a si mesmos o embargo de um tratamento de laboratório das bactérias, sob o pretexto de que se as fazem demasiadamente fortes elas poderiam escorregar por debaixo da porta e arrasar pelo menos com toda experiência sexuada, arrasando com o falasser [...]...(Lacan, 1975, p. 187).

E então Lacan situa exatamente o que está em jogo, a tentativa do cientista de dar conta do impossível, ali onde a bactéria retorna para ele sob sua face mais angustiante, a que denuncia que a vida, no fim das contas, é toda ela uma infecção, na medida em que tudo só obedece à implacável ordem entre vida e morte, vida que para na fascinação do olhar mortal que a ficção científica devolve ao cientista angustiado com o fato de que a ciência não dará conta jamais de resolver isso. Afirma que "Esse acesso de responsabilidade [que os cientistas assumem ao embargar uma experiência] é incrivelmente cômico; toda a vida reduzida à infecção que ela realmente é, isso é o cúmulo do ser pensante!" (Lacan, 1975, p. 188).

Embora muitas das descobertas no campo científico carreguem a autoria de seus descobridores, boa parte resta anônima nos dias de hoje, tal a velocidade que a técnica cobra para lançar produtos no mercado. Entre Deus e a ciência, entre a salvação e a cura, retornamos àquilo que é central, aquilo que não cessa de não se inscrever, o real do gozo.

O inconsciente é os efeitos da fala sobre o sujeito (Lacan, 1964/1985a), o que resulta de um lado num inconsciente estruturado como uma linguagem e, de outro lado, num inconsciente real, campo do gozo e de lalangue - nem signans nem signatum, como diziam os estóicos -, e sim, lugar onde se goza o fato de o inconsciente ser estruturado como uma linguagem (Lacan, 1975).

A Psicanálise, como laço entre duas pessoas, está no lugar da falta da proporção ou relação sexual (Lacan, 1975), falta que inicialmente ficara colmatada na tentativa de encobrir tal enigma, mas retomando-o no Yin e Yang da ciência que se fazia numa época muito remota. Com o advento da ciência moderna, no entanto, se dá sua emergência! Enigma: o desejo no texto freudiano, presentificado na esfinge do mito de Édipo, surge num momento preciso da história como o que fura, o que faz vacilar, colapsa.

A partir desse colapso, evolui ao curso da história. E o sujeito, o sujeito da ciência, de repente emerge disso, como se sempre estivesse estado aí, mas nunca antes reparado, ele é a falta da 
relação que até então sempre fora recoberta no lugar em que o pensamento se juntava com a realidade sexual. Freud o capta no desejo que se sustenta porque há psicanalista. Porque no fundo, 0 desejo, a partir do discurso da ciência, garante um mais além dele ou um mais aquém - guardando a marca do impossível.

Se nos ativermos às quatro categorias de Aristóteles, o necessário, o impossível - as duas universais -, o possível e o contingente - as duas particulares -, a emergência do sujeito a partir do discurso da ciência é o contingente através do qual o impossível cessa de não se escrever. Particular negativa, atualmente de grande interesse no campo da biologia - e toda teoria evolucionária. Mas que, por ser ciência, também ela produz mal-estar e, portanto, uma nova emergência subjetiva que a Psicanálise poderá tratar que tratar.

Ancorado em Freud, Lacan ainda irá reafirmar a questão que a natureza do inconsciente coloca diante de nós, "a de que alguma coisa sempre pensa e que o inconsciente está acima de todos os pensamentos e que aquilo que pensa está vedado à consciência" (Lacan, 1976, p. 201). Desta forma, firmemente apoiado na divisão psíquica, é que Lacan ressaltará a impossibilidade da unidade totalizadora do sujeito, considerando mesmo uma mentira escandalosa tal proposição. Não é possível pensar em um indivíduo, numa unidade, quando a própria experiência do ato de viver diz que a vida é algo sem precisão, ao contrário do navegar que conta com instrumentos precisos para indicar por onde ir. A vida segue à deriva, isto é, por conta da pulsão. Dessa forma, Lacan afirma que

Jamais pude compreendê-lo, pois, embora eu seja um psicanalista, sou também um homem e minha experiência me diz que a principal característica de minha vida humana e, certamente, das vidas de todos os presentes - e se alguém pensar assim, espero que se manifeste - é que a vida é algo que vai, como dizemos em francês, à la derive (Lacan, 1976, p. 202).

Estando à deriva, guiado pela pulsão, impulsionado pelo gozo, não se pode pretender fazer de qualquer sujeito um barco de rumo certo ou um terreno plano, linear, aplainando seus relevos. A clínica do malestar faz persistir nessa via. De forma alguma se visa com ela um pessimismo, ao contrário, seu corolário é o entusiasmo, efeito de fazer valer, finalmente, essa emergência que é o sujeito do desejo! Entusiasmo que nos moveu a escrever aqui.

Assim, pensando epistemologicamente, podemos dizer que foi necessário que Hegel pensasse a consciência como linguagem para que Freud pudesse pensar uma linguagem inconsciente e Lacan pudesse afirmar o inconsciente estruturado como uma linguagem e chegasse ao inconsciente real, concluindo que o sujeito é o vazio 
onde irá deslizar a cadeia de significantes e que remete ao real da pulsão.

\section{Considerações abertas}

O lugar ocupado pela Psicanálise na cultura contemporânea é fundamental, pois é dela que emana a possibilidade de se manter aberto o lugar do sujeito e o vigor de uma ética centrada no desejo. É a Psicanálise que hoje restitui ao sujeito seu lugar, ela ainda é a melhor opção que nós temos para lidar com o mal-estar inarredável na cultura.

Mas o quê podemos esperar de nossa época? Sustentando uma clínica que não busca eliminar o ineliminável mal-estar, o que pode a Psicanálise no século XXI?

Lacan admitiu (2003e), na entrevista dada à televisão, que no futuro próximo a Psicanálise talvez perdesse para a religião. Antecipou também a escalada do racismo como algo, infelizmente, da ordem da verdade. Não estamos vendo nada muito diferente. Inúmeras manifestações da virulência da pulsão de morte, desfusionada da pulsão sexual, são flagradas a cada dia. A questão ética que se coloca é como trabalhar clinicamente com ela ou o que tem a dizer o psicanalista, sem fugir de sua responsabilidade, sobre o porquê de tal acontecimento nesse momento da cultura. Se a Psicanálise tem como objeto a falta, como pensar em uma cultura em que os sujeitos utilizam-se de todos os meios para aboli-la, da tecnologia às drogas, da moda ao semelhante? (Barros, 1999, p. 266).

A Psicanálise surgiu no império da razão. Isso coincidiu com a ideologia que fez do progresso oferecido pela ciência o horizonte de bem-estar e conforto. O produtivismo e sua sequela, o consumismo, ergueram-se para tentar suturar a fenda estrutural do homem. Fazendo eco a essa obturação alienante, a Psicanálise surgiu num momento histórico, numa Viena em que tudo era vanguarda e, entre outras reações à tentativa de obturação da fenda estrutural, se tornou um "sintoma-denúncia" de um resto indestrutível, deixando claro para o sujeito a irrecuperabilidade de um bem-estar absoluto. Nesse sentido, a Psicanálise sustenta que, de todos os recursos de que dispomos, apenas um é essencial: a palavra, aquela que compromete integralmente quem a profere, da mesma forma que transforma quem a escuta.

Podemos sustentar, apoiados no pensamento freudiano e lacaniano, que a Psicanálise é uma das poucas modalidades de tratamento da alma que não vê o ser humano como um objeto desabitado. É uma das mais poderosas ferramentas criadas pelo homem para eliminar 0 sofrimento humano desnecessário. É o precioso bem que, ao tratar a dor neurótica, não nivela o homem a um débil joguete do Outro, seja 
este Outro chamado ciência, religião, mercado ou o que se quiser. Se há algo que podemos esperar da Psicanálise, como uma promessa ou um compromisso ético, é que levará o sujeito ao encontro da sua verdade, em que pesem as ilusões.

\section{Referências}

Alberti, S. \& Elia, L. (2008). Psicanálise e Ciência: o encontro dos discursos. Revista Mal Estar e Subjetividade, 8(3), 779-802. Recuperado em 03 de maio de 2018, de http://pepsic.bvsalud.org/scielo.php?script=sci_arttext\&pid=S1 $518-61482008000300010 \&$ Ing $=p t \&$ tIng $=$ pt.

Alberti, S., Corrêa, A. F., Costa, A. C. (2014). O ódio e a ex-sistência. In Dominios de la violencia, territorios del odio: psicoanálisis y campo social (pp. 93-102). Valparaíso, Chile: Universidad Andrés Bello.

Barros, R. M. M. de (1999). A promessa analítica e o mal-estar na cultura. Tese de doutorado, Universidade Federal do Rio de Janeiro, Rio de Janeiro, RJ, Brasil.

Barros, R. M. M. de (2012). A Psicanálise e sua inserção no discurso da ciência. In Santos, T. C. dos; Santiago, J.; Martello, A. De que real se trata na clínica psicanalítica? Psicanálise, ciência e discursos da ciência. (pp. 81-108). Rio de Janeiro: Cia de Freud: PROAP/CAPES.

Barros, R. M. M. de (2016). A arte, o gozo feminino e o mal-estar na contemporaneidade. Revista Affectio Societatis, 13(24) (pp. 123-139). Medellín, Colombia: Departamento de Psicoanálisis, Universidad de Antioquia. Recuperado em 10 de abril de 2016 de

http://aprendeenlinea.udea.edu.co/revistas/index.php/affectios ocietatis

Braunstein, N. (2011). 48 variações sobre o tema da 'moral sexual'. In Braunstein, N. \& Fuks, B. B. (Org.). 100 anos de novidade A moral sexual "cultural" e o nervosismo moderno, de Sigmund Freud [1908-2008] (pp. 40-51). Rio de Janeiro: Contra Capa.

Figueiredo, A. C. (2011). O psicanalista na experiência universitária. In Caldas, H. \& Altoé, S. Psicanálise, universidade, sociedade. (pp. 185-198). Rio de Janeiro: Cia de Freud: PGPSA/IP/UERJ.

Fink, B. (1998). O sujeito lacaniano: entre a linguagem e o gozo. Rio de Janeiro: Jorge Zahar.

Freud, S. (1974). O mal-estar na civilização. In Freud, S. Edição standard brasileira das obras psicológicas completas de Sigmund Freud, v. XXI (pp. 81-177). Rio de Janeiro: Imago. (Trabalho original publicado em 1930). 
Freud, S. (1975a). Sobre o ensino da Psicanálise nas universidades. In Freud, S. Edição standard brasileira das obras psicológicas completas de Sigmund Freud, v. XVII (pp. 217-223). Rio de Janeiro: Imago. (Trabalho original publicado em 1918).

Freud, S. (1975b). A questão da análise leiga. In Freud, S. Edição standard brasileira das obras psicológicas completas de Sigmund Freud, v. XX (pp. 211-288). Rio de Janeiro: Imago. (Trabalho original publicado em 1926).

Freud, S. (1975c). Esboço de Psicanálise. In Freud. S. Edição standard brasileira das obras psicológicas completas de Sigmund Freud, v. XXIII (pp. 168-245). Rio de Janeiro: Imago. (Trabalho original publicado em 1938).

Freud, S. (1975d). Freud - Lou Andreas-Salomé. Correspondência completa. Rio de Janeiro, Imago.

Freud, S. (1976a). Moral sexual 'civilizada' e doença nervosa moderna. In Freud, S. Edição standard brasileira das obras psicológicas completas de Sigmund Freud, v. IX (pp. 187-211). Rio de Janeiro: Imago. (Trabalho original publicado em 1908).

Freud, S. (1976b). Recordar, repetir, elaborar. In Freud, S. Edição standard brasileira das obras psicológicas completas de Sigmund Freud, v. XII (pp. 193-206). Rio de Janeiro: Imago. (Trabalho original publicado em 1914).

Jorge, M. A. C. \& Ferreira, N. P. (2005). Lacan, o grande freudiano. Rio de Janeiro: Jorge Zahar.

Jorge, M. A. C. (2011). 1905-1908: a subversão freudiana, de "Três ensaios sobre a teoria da sexualidade" a "Moral sexual 'cultural'". In Braunstein, N. \& Fuks, B. B. (Orgs.). 100 anos de novidade - A moral sexual "cultural" e o nervosismo moderno, de Sigmund Freud [1908-2008], (pp. 53-72). Rio de Janeiro: Contra Capa.

Lacan, J. (1975.) La troisième. Lettres de l'EFP (16) (pp. 178-203).

Lacan, J. (1976). Da estrutura como intromistura de um pré-requisito de alteridade e um sujeito qualquer. In Macksey, R. \& Donato, E. (Orgs.). A controvérsia estruturalista. (pp. 198-212). São Paulo: Cultrix. (Trabalho original publicado em 1966).

Lacan, J. (1981). Le malentendu. Ornicar?, Paris, Lyse (n.22-23), 1434.

Lacan, J. (1985a). O seminário, livro 11: Os quatro conceitos fundamentais da Psicanálise. Rio de Janeiro: Jorge Zahar. (Seminário ministrado em 1964).

Lacan, J. (1985b). O seminário, livro 20: Mais, ainda. Rio de Janeiro: Jorge Zahar. (Seminário ministrado em 1972/1973).

Lacan, J. (1988). O seminário, livro 7: a ética da Psicanálise. Rio de Janeiro: Jorge Zahar. (Seminário ministrado em 1959-1960). 
Lacan, J. (2003a). O discurso de Roma. In Lacan, J. Outros escritos. (pp.139-172). Rio de Janeiro: Jorge Zahar. (Trabalho original publicado em 1958).

Lacan, J. (2003b). Apresentação das Memórias de um doente dos nervos. In Lacan, J. Outros escritos. (pp. 219-223). Rio de Janeiro: Jorge Zahar. (Trabalho original publicado em 1966).

Lacan, J. (2003c). Alocução sobre as psicoses da criança. In Lacan, J. Outros escritos. (pp. 361-368). Rio de Janeiro: Jorge Zahar. (Trabalho original publicado em 1967).

Lacan, J. (2003d). Prefácio a uma tese. In Lacan, J. Outros escritos. (pp. 389-399). Rio de Janeiro: Jorge Zahar. (Trabalho original publicado em 1970).

Lacan, J. (2003e). Televisão. In Lacan, J. Outros Escritos. (pp. 508 543). Rio de Janeiro: Jorge Zahar Editor. (Trabalho original publicado em 1973).

Lacan, J. (2009). O seminário, livro 18: De um discurso que não fosse semblante. Rio de Janeiro: Jorge Zahar. (Seminário ministrado em 1971).

Lacan, J. (2012). O seminário, livro 19: ...ou pior. Rio de Janeiro: Jorge Zahar. (Seminário ministrado em 1971/1972).

Laurent, E. (2016). O avesso da biopolítica: uma escrita para o gozo. Rio de Janeiro: Contra Capa.

Lemoine-Luccioni, E. (1979). Le partage des femmes. Paris: Seuil.

Milner, J. C. (1996). A obra clara: Lacan, a ciência e a filosofia. Rio de Janeiro: Jorge Zahar.

Pigeaud, J. (2008). Melancholia. Paris: Payot.

Rey-Flaud, H. (2002). Os fundamentos metapsicológicos de 'O malestar na cultura'. In Le Rider, J. et alii. (Orgs.). Em torno de $\mathrm{O}$ mal-estar na cultura, de Freud (pp. 05-68). São Paulo: Escuta.

Roudinesco, E. (2000). Por que a Psicanálise? Rio de Janeiro: Jorge Zahar.

Sêneca. (2010). Da tranquilidade da alma. Porto Alegre: LP\&M.

Vico, G. (1974). Princípios de uma ciência nova. São Paulo: Abril. (Obra original publicada em 1725).

\section{Endereço para correspondência \\ Rita Manso}

Universidade do Estado do Rio de Janeiro

Instituto de Psicologia

Rua São Francisco Xavier, 524, 10 andar, CEP 20550-900, Rio de Janeiro - RJ, Brasil

Endereço eletrônico: ritamanso2008@gmail.com

\section{Marco Antonio Coutinho Jorge}

Universidade do Estado do Rio de Janeiro

Instituto de Psicologia

Rua São Francisco Xavier, 524, 10 andar, CEP 20550-900, Rio de Janeiro - RJ, Brasil

Endereço eletrônico: macjorge@corpofreudiano.com.br 


\section{Sonia Alberti}

Universidade do Estado do Rio de Janeiro

Instituto de Psicologia

Rua São Francisco Xavier, 524, 10 andar, CEP 20550-900, Rio de Janeiro - RJ, Brasil

Endereço eletrônico: sonialberti@gmail.com

Recebido em: 07/01/2015

Reformulado em: 04/06/2017

Aprovado em: 20/06/2017

\section{Notas}

* Professora Associada do Instituto de Psicologia e do Programa de Pós-graduação em Psicanálise da Universidade do Estado do Rio de Janeiro, UERJ. Professora Titular do Departamento de Fundamentos da Educação da Universidade Federal do Estado do Rio de Janeiro, UNIRIO. Psicanalista. Organizadora dos livros Psicanálise e saúde: entre o Estado e o sujeito (com Vinicius Darriba, 2015) e Estrutura e Psicanálise (com Luciano Elia, 2013) publicados pela Cia. de Freud.

** Professor Associado do Instituto de Psicologia e do Programa de Pós-graduação em Psicanálise da Universidade do Estado do Rio de Janeiro, UERJ. Psicanalista, psiquiatra, Membro do Corpo Freudiano Escola de Psicanálise. Autor de, entre outros livros, Fundamentos da Psicanálise de Freud a Lacan, vol. 1: as bases conceituais (2000), vol. 2: a clínica da fantasia (2010), publicados pela Editora Zahar.

*** Professora Associada do Instituto de Psicologia e do Programa de Pósgraduação em Psicanálise da Universidade do Estado do Rio de Janeiro, UERJ. Procientista da UERJ, Preceptora da Residência em Psicologia Clínica Institucional do IP/UERJ e Pesquisadora do CNPq. Psicanalista Membro da Escola de Psicanálise dos Fóruns do Campo Lacaniano. Autora de, entre outros, Esse sujeito adolescente (1996). 